\title{
Our education system has failed to prepare us to innovate society in preparation for disruptive future technology by Anonymous (he/they)
}

I graduated from an engineering-focused undergraduate education into the social isolation of the pandemic and, with my planned job opportunities defunded, I had time to think about what I want to do with my life. I asked myself where I want to be in 35 years so I could have some idea about which direction to go to get there, but there was a problem. I couldn't place myself 35 years in the future because I didn't know what the future would be like. So I looked at current and past trends to attempt to project into the future. This was admittedly a task of speculation, but with enough data, was highly informed.

What I found was a history of greed-induced negligence from those in power being irresponsible for the negative effects of their unsustainable policies and a future dominated by these effects and the effects of the exponential growth of technology. Retrospectively, this seems obvious but was alarming at the time, snapping me out of the enticing engineering career narrative trance. Due to the nature of exponential growth, technological developments will soon compound so quickly that our social and political institutions will become overwhelmed if they do not innovate to embrace a new pace of change. If our social systems cannot innovate, then quarterly-earningsfocused corporations will make far more massive profits from unregulated technology at everyone's expense. This will lead to all sorts of problems, which we are already starting to see: enhanced perpetuation of social ills and increased existential anthropogenic global catastrophic risks. Having just finished my experience within the education system with a focus on building new technology, I am not prepared to creatively innovate for social equity in this reality, and my peers are unprepared as well. We were educated to be obedient defense contractor workersproductive members of a stable mythical reality of the past. Our new reality requires radical social innovation soon if we are to have any chance to thrive equitably in the future.

Before I graduated, I was more of a techno-optimist; I was not bothered by the world's problems because I had faith that new technology would solve them. I now realize that our biggest challenges cannot be solved with technology alone because doing so is often not profitable, so it won't be funded. The future will not be like the past, so approaching the future with social institutions designed for the past will not necessarily be effective. Solutions to these problems primarily require social, economic, and political change, which is far slower and more difficult to achieve than technological development. In response to this revelation, I have become interested in learning about the complexities involved in our social institutions. I would like to apply this understanding, combined with my knowledge about technology, toward scalable social impact projects that contribute to solving some of these problems, and hopefully I will find a supportive, diverse, and interdisciplinary community in the process.

So, with my research so far, what should we do to ensure a better future? I don't know the details yet, but I have some ideas. I think it will have something to do with designing an emergent system with the following components: interdisciplinary new organizations, social consciousness, rampant sharing of intellectual property, continuing education for technological literacy, emergence of global behavior through local agent interactions, intersectionality, complex systems analysis, applied novel technology, reduction of corporate money in politics, strong ethical 
foundations, diverse sustainable communities, circular economy paradigms, democratization of the means to make new technology, decentralized regulation frameworks, local accessible manufacturing with global expertise, a completely new paradigm for education and accessible information, leadership in ethical innovation, open-source business plans, adoption of regulated automation, democracy of educated citizenry, support for small open venture interventions, grassroots emergent change, self-replicating organizations, dismantling of illegitimate authority, shifting of power from corporations to common people, and rethinking of the social institutions surrounding new technological developments.

The most shocking part so far? It took a year of social isolation in a pandemic to interrupt my life to the point that I had the mental energy available to start to think for myself and stop following the narrative I was taught. The existing paradigm is self-perpetuating and this presents a challenge that engineers like me are not prepared to solve. 